\title{
Correction to: Breeding Differently: Participatory Selection and Scaling Up Innovations in Colombia
}

\author{
Teresa Mosquera Vásquez ${ }^{1}$. Sara Del Castillo ${ }^{2}$. \\ Luis Ernesto Rodríguez ${ }^{1}$. David Cuéllar Gálvez ${ }^{1}$
}

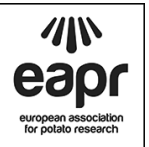

Published online: 19 October 2018

C) European Association for Potato Research 2018

Correction to: Potato Research (2017) 60:361-381

https://doi.org/10.1007/s11540-018-9389-9

The original version of this article unfortunately requires correction with respect to the order of authors. The correct order of authors should be:

Teresa Mosquera Vásquez ${ }^{1}$ Sara Del Castillo ${ }^{2}$ Luis Ernesto Rodríguez ${ }^{1}$ - David Cuéllar Gálvez ${ }^{1}$

The online version of the original article can be found at https://doi.org/10.1007/s11540-018-9389-9

Teresa Mosquera Vásquez

tmosquerav@unal.edu.co

1 Universidad Nacional de Colombia, sede Bogotá, Faculty of Agricultural Sciences, Bogotá, Colombia

2 Universidad Nacional de Colombia, sede Bogotá, Faculty of Medicine, Bogotá, Colombia 